\title{
Two-Way, One-Way or Dead-End Streets? Financial and Social Causes and Consequences of Generalized Trust
}

\author{
Stefan Leenheer ${ }^{1} \cdot$ Maurice Gesthuizen $^{2}$ (D) $\cdot$ Michael Savelkoul $^{2}$
}

Accepted: 9 December 2020 / Published online: 8 February 2021

(c) The Author(s) 2021

\begin{abstract}
Scholars disagree on whether and to what extent adult life experiences can influence generalized trust and vice versa. Going beyond the methodological limitations of former studies, we aimed to answer the question as to what extent reciprocal causal relationships exist between generalized trust and the adult life experiences of financial success and (in)formal social contacts. We used two-wave cross-lagged panel models to identify those reciprocal causal relationships, and fixed-effects models to assess if they might be biased due to unaccounted time-invariant influences. Data from the Dutch NELLS panel study (age range 17-49) show that compelling empirical evidence is found for a reciprocal causal relationship between generalized trust and household income that does not suffer from bias due to unobserved heterogeneity. Furthermore, more trusting individuals experience a stronger decrease in material deprivation, but not vice versa. Trust and (in)formal social contacts are not causally related in any of our models.
\end{abstract}

Keywords Generalized trust $\cdot$ Financial success $\cdot$ Social contact $\cdot$ Cross-lagged panel models $\cdot$ Fixed-effects models

\section{Introduction}

Generalized (social, horizontal, thin, moralistic, impersonal) trust can be regarded as the beliefs that people hold about how other, mostly unknown people in society will in general act towards them (Delhey and Newton 2005; Uslaner 2002; Nannestad 2008), ranging from at worst, the belief that others in general will not knowingly or willingly do them harm, and at best, the belief that others in general will act in their interests (Delhey and Newton 2003). It is celebrated for its pragmatic value of acting as a social cement, contributing to the existence and maintenance of ties between increasingly heterogeneous individuals and groups, as well as its potential to overcome collective action problems (Fukuyama 1995). Not only can generalized trust thus be seen as an indicator of social cohesion, but also of

Maurice Gesthuizen

m.gesthuizen@maw.ru.nl

1 GBTwente, Hengelo, The Netherlands

2 Department of Sociology, Radboud University, P.O. Box 9104, 6500 HE Nijmegen, The Netherlands 
how well a society functions. And of course, generalized trust is thought to be a-if not the-core component as well as indicator of social capital (Putnam 2000).

Indeed, many studies find that a higher level of generalized trust correlates with benefits on an individual and a societal level. On an individual level, it is associated with better financial and educational outcomes, more civic engagement, and better health (e.g., Dauner et al. 2015; Delhey and Newton 2003; Nakhaie and Arnold 2010; Putnam 2000). On a societal level, it coincides with lower crime rates, more economic growth, and more effective governments (e.g., Knack and Keefer 1997; Messner et al. 2004; Ritzen et al. 2000). Because generalized trust seems to be crucial to the social and economic prosperity of individuals and communities as well as the democratic functioning of societies, it deserves to be understood in terms of how it can be developed, nurtured and maintained (Sturgis et al. 2012).

Despite these apparent benefits and the relatively large amount of research that has been devoted to the topic, still many knowledge gaps exist regarding generalized trust. Scholars for instance disagree whether and to what extent generalized trust reflects a fixed personality trait or an individual characteristic subject to change. Uslaner (2002) argues that generalized trust is a highly stable personality trait, set in stone after the formative years, and comparable to other fixed traits, such as honesty and optimism (see also Glanville and Paxton 2007). It is thus unlikely to be changed by adult life experiences. Any observed associations between such experiences and generalized trust are therefore considered to be spurious in that they are due to unobserved differences in sociability, i.e., a 'joiner nature' (Glanville et al. 2013; Stolle 2001; Sturgis et al. 2012). Yet, others (e.g., Brandt et al. 2015; Delhey and Newton 2003) propose that generalized trust is (at least partly) influenced by adult life experiences. This line of research, however, suffers from an unresolved matter of causality. Delhey and Newton (2003: 102) note that there is a severe chicken-and-egg problem with most theories and empirical findings about trust: 'In almost every association between trust and another variable, the link may be one of cause or effect, or both. For example, [...] wealth may be associated with trust because it helps to risk, or because trust encourages economic growth.' Likewise, while active formal and informal social contacts are presumed to foster generalized trust, the causality may very well flow in reverse in the sense that some base level of trust is needed for a person to join a club or make some meaningful connection with another individual (Glanville et al. 2013; Sturgis et al. 2012).

This study aims to provide an overview and a better understanding of-possibly reciprocal - causal relations between generalized trust and a broad range of social phenomena, previously linked to generalized trust. Prior research usually focuses on the interrelations between generalized trust on the one hand, and either social ties or financial success on the other. We opt for providing an as broad picture as possible, by including valid measurements of objective and subjective financial success (i.e., income and material deprivation) as well as indicators of social capital (i.e., informal and formal social contacts). We aim to answer the following research question: To what extent do reciprocal causal relationships exist between generalized trust and indicators of financial success and (in)formal social contacts? To answer this question, we use panel data from the NEtherlands Longitudinal Lifecourse Study (NELLS), which is a large-scale two-wave panel survey (Tolsma et al. 2014), and contains a wide array of valid indicators for our central concepts of generalized trust, financial success and social capital.

Our central aim of providing a broad overview and a better understanding of (reciprocal) causal relations translates into several contributions to the field. First, it brings together several theoretical branches, to formulate expectations on financial and social causes and consequences of generalized trust. Second, for the Dutch context, ages 17-49, empirical evidence will give an answer to the chicken-and-egg question, providing insights as to 
where the fruits of trust are a two-way, one-way, or a dead-end street. As previous research (e.g., Putnam 2000) has indicated the interrelatedness of the central concepts in our study (i.e., financial success, social contacts and generalized trust), we do not only consider relationships between generalized trust and each single indicator separately, but-unlike earlier research-also more rigorously test models in which we take all indicators into account simultaneously. This enables us to assess the unique contribution of each indicator. We will abstain from theorizing on the interrelatedness of our indicators and possible mediation effects, though we will come back to this in our discussion section.

Longitudinal panel data on a broad range of social, economic and attitudinal phenomena are scarce. Our primary reason to use the NELLS-panel is because it contains this broad range of indicators. Ideally, one would like to have access to at least three waves, to be able to simultaneously infer on reciprocal causality and to rule out unobserved heterogeneity bias (the next paragraph discusses these issues in relation to the literature on economic and social causes and consequences of trust). A back draw of the NELLS-panel is, that there are only two waves. Therefore, we need to separately estimate two-wave cross-lagged panel models using structural equation modelling (SEM), to infer causality, and fixed-effects models to rule out any unobserved heterogeneity in the causal relationships that were found in the two-wave cross-lagged panel models. As we need both approached-there is no superior one because both have their unique strengths and weaknesses (see below) - throughout this research we follow the strategy that a reciprocal causal relationship exists only if the cross-lagged panel model shows significant paths to and from generalized trust and the fixed-effects models show that both paths do not suffer from unobserved heterogeneity bias.

Doing so, we find compelling empirical evidence for a reciprocal causal-two-way street-relationship between generalized trust and household income that does not suffer from bias due to unobserved heterogeneity. Furthermore, more trusting individuals experience a stronger decrease in material deprivation, but not vice versa, trust thus representing a one-way street here. Additionally, even though cross-lagged panel findings suggest a reciprocal causal relationship between trust and formal social contacts, fixed-effects findings indicate that they may well be due to unobserved heterogeneity bias. Trust and informal social contacts are not causally related in any of our models. For (in)formal social contacts, trust seems to be a dead-end street.

\section{Previous Findings and Theoretical Expectations}

Although scholars often acknowledge that generalized trust is likely to operate as both a cause and an effect, empirically the causal relationship between trust and other social phenomena is generally modeled in a unidirectional manner. While the vast majority of studies used cross-sectional data (e.g., Brehm and Rahn 1997; Delhey and Newton 2003; Knack and Keefer 1997; Paxton 2007; Stolle 1998) and are, thus, empirically unable to disentangle causal relationships, more recent research based on longitudinal data (e.g., Sturgis et al. 2012; Van Ingen and Bekkers 2015) often neglects reciprocal relations. Generally, these cross-sectional and longitudinal panel studies use linear regression analyses to assess relationships between generalized trust and social phenomena like financial success and (in) formal contacts. One of the crucial assumptions of this technique is that the independent variables are uncorrelated with the disturbances of the dependent variable, which implies that the dependent variable does not affect the independent variables. In case of reciprocal causation, this assumption is violated, making effect estimates biased and inconsistent 
(Gujarati 2003). Given the likelihood that the causality between generalized trust and social phenomena like financial success or (in)formal social contacts flows both ways, it is clear that controlling for reciprocal effects between trust and these concepts is nothing short of a necessity, if one is to produce unbiased and consistent effect estimates.

To our knowledge, there are only three longitudinal studies that have examined reciprocal relations between the concepts of generalized trust, financial success and (in)formal social contact (Brandt et al. 2015; Claibourn and Martin 2000; Glanville et al. 2013). Using cross-lagged panel models, these studies were able to disentangle causal relationships more profoundly. Overall, these studies suggest that the effects of financial success and social contact on trust are stronger than the reverse. Although these studies provide important contributions in understanding the causes and consequences of generalized trust, cross-lagged panel models are sensitive to unobserved heterogeneity, as unobserved confounders may cause unobserved heterogeneity bias (i.e., omitted-variable bias) of the estimates (Allison 2005b). Fixed-effects models can solve this problem by partialling out the influences of all observed and unobserved time-invariant (i.e., 'fixed') characteristics of individuals, confounding or not (Allison 2005b). These time-invariant characteristics not only include indicators like sex or ethnicity, but also the less easily measurable variables of personality traits and formative experiences. Therefore, fixed-effects models allow for testing the notion that relationships between generalized trust and its correlates are spurious due to-among other things - unaccounted differences in sociability (Uslaner 2002).

Recently, several studies used fixed-effects models to test whether or not there is any merit to this idea in regards to relationships between trust and indicators of formal and informal social contacts. While some do find these relationships to be present (Glanville et al. 2013), most researchers conclude that the relationships between generalized trust and (in)formal social contact indicators are spurious after partialling out the effects of unobserved time-invariant characteristics (Bekkers 2012; Sturgis et al. 2012; Van Ingen and Bekkers 2015). Although these studies are able to rule out any unobserved heterogeneity, they do not take into account reversed causality, introducing biased estimates. Furthermore, to the best of our knowledge, so far no study has applied a fixed-effects approach for the relationships between generalized trust and financial success.

In this study, we thus apply both analysis strategies to assess causal relationships between generalized trust and financial success and (in)formal social contacts more accurately. Below, we will use earlier theoretical insights and empirical findings to derive testable hypotheses.

\subsection{Financial Success and Generalized Trust}

Reciprocation is a basic tenet of social interaction: I (the trustor) do something for you (the trustee) in the hope that you return the favor. This action carries risk, since the trustee may choose to not reciprocate, thus leaving the trustor at a disadvantage. The level of risk varies between members of society. In general, one may expect that the 'winners' in society tend to trust more than the 'losers', because they can better cope with the negative consequences of non-reciprocation (Delhey and Newton 2003; Putnam 2000). Not surprisingly, individuals with larger amounts of income are expected to trust more than those with lower amounts, since they can better meet their basic needs for living in case of exploitation (Delhey and Newton 2003; Hamamura 2012).

Indeed, an abundance of cross-sectional studies have demonstrated that the level of generalized trust is significantly higher among the economically better-off individuals 
in society (e.g. Alesina and La Ferrara 2002; Almakaeva et al. 2014; Delhey and Newton 2003; Hamamura 2012; Knack and Keefer 1997). Using cross-lagged panel models, Brandt and colleagues (2015) demonstrated that higher levels of income predict significant increases in generalized trust, without finding support for a reversed effect.

Closely related is the literature on material deprivation. In this line of thought, it is not how much financial resources one has per se that dictates his or her level of (dis) trust, but rather how much one has in relation to another individual. Material deprivation can be seen as the inability for individuals or households to afford those consumption goods and activities that are typical in a society at a given point in time, irrespective of people's preferences with respect to these items (Whelan et al. 2001). Not being able to fulfill societal norms of behavior due to material deprivation is considered to cause 'anomic' conditions, that is, a mismatch between the individual's position and societal norms (Durkheim 1964[1893]). Such conditions evoke emotions of anger, inadequacy, and envy, together with perceptions of inequality. In turn, these emotions and perceptions manifest as untrustworthy behavior and distrust (Merton 1938). Studies that provide direct empirical evidence of these notions are hard to come by. The few studies that are available showed that negative emotions are indeed associated with lower levels of trust (Dunn and Schweitzer 2005; Weining and Smith 2012). Generally, empirical findings do strongly suggest that material deprivation is more strongly associated with, among others, having health problems, experiencing anxiety, and sleeplessness, than having a low income (Halleröd and Larsson 2008). As such, material deprivation seems to be more closely related to experiencing financial hardship than (having a low) income.

In reverse, generalized trust is expected to influence financial success through the creation of social capital. While conceptualizations of social capital are varied, the general idea behind the concept is that it is useful. According to Lin's $(2001,2005)$ theory on social capital, investing in and trusting others helps us to gain access to their resources, such as wealth, information and influence. These resources can then be borrowed and used to improve our position on the social ladder. In turn, we become more trustful due to our newfound status, enabling us to reap more benefits, leading to even more trust, and so forth. A virtuous circle is therefore said to exist between trust, social contacts, and financial success (Putnam 2000). A vicious circle is, of course, also possible. Individuals who do not trust others might end up socially isolated, thus damaging the amount of resources they can obtain and enabling the formation of distrust.

The link between generalized trust and financial success (in terms of income) has been investigated extensively. As mentioned before, cross-sectional studies generally confirm that this relation is present. Longitudinal studies on this topic are, however, quite rare. An exception is the study of Brandt et al. (2015), in which a cross-lagged panel model showed no causal effect of trust on income. The link between generalized trust and material deprivation has not been investigated before.

In summary, based on the theoretical notions above, partly underscored by previous findings, we expect our cross-lagged models-accounting for reverse causation bias- to show reciprocal causal relationships between household income and material deprivation on the one hand and generalize trust on the other, that is: Hla; the higher the income the stronger the increase in generalized trust; H1b; the higher the level of generalized trust, the stronger the increase in income; $\mathrm{H} 2 \mathrm{a}$; the higher the level of material deprivation, the stronger the decrease in generalized trust, and $H 2 b$; the higher the level of generalized trust, the stronger the decrease in material deprivation, and we expect our fixed-effects models to indicate these relationships to be free from unobserved heterogeneity bias. 


\section{2 (In)formal Social Capital and Generalized Trust}

Social contact, both formal and informal, is thought to encourage the development of generalized trust through ongoing social interactions (Delhey and Newton 2003; Putnam 2000). Informal networks primarily consist of friendship or extended familial contacts (Granovetter 1973). Formal contacts are gained by participating in formally constituted civic organizations (Putnam 2000). Of course, social contacts are expected to help develop trust only when the interactions with network members are positive. It is presumed that people, in general, are rational and display cooperative and trustworthy behavior during interactions in order to maximize their utility, a notion that is often supported by experiments (see review by Gächter 2006; Colman 2003). Regular interactions with friends, family, and community members should therefore facilitate the sense that these contacts will fulfill their obligations when the time comes to reciprocate, thus building trust (Welch et al. 2007).

There are two notions, however, that make it difficult to understand how social contact-in both formal and informal networks-allows for the creation of generalized trust, instead of more particularized trust (Uslaner 2002). First, we tend to have at least some rudimentary knowledge of those whom we interact with, reducing the necessity to make assumptions regarding the other's future behavior. Second, the social contacts we have tend to be homophilous, because we like to congregate with those who are similar to ourselves (McPherson et al. 2001), that is, people whose trustworthiness can be easily judged, based on our introspection. Both notions suggest that by joining or having a certain network, we tend to '... reinforce particularized trust (in ego's own kind) rather than generalized trust' (Uslaner 2002: 5). To cross the gap between particularized and generalized trust, scholars assume that particularized trust has a spill-over effect (Glanville et al. 2013; Putnam 2000; Rosenblum 1998; Stolle 1998). In other words, regular interaction with certain individuals is expected to not only boost the sense that these particular people can be trusted, but also the sense that people in general are trustworthy (Welch et al. 2007). Evidence suggests that a spill-over effect from particularized trust to generalized trust exists (Freitag and Traunmüller 2009; Glanville and Paxton 2007).

Virtually all of the cross-sectional studies find a positive relationship between social contact and generalized trust (see Delhey and Newton 2003; and Van Ingen and Bekkers 2015).

In this line of research, there is more evidence available from longitudinal studies, which is, however, mixed. Using cross-lagged panel models, Glanville and colleagues (2013) show that the more often people socialize with informal contacts (friends, relatives, neighbors), the higher their increase of generalized trust is. No support, however, was found for the return effect from trust to informal social contacts. For a sample of parents, Claibourn and Martin (2000) found no support for a causal relationship between group memberships and generalized trust (or vice versa) using cross-lagged panel models. Yet, they did find weak evidence for synchronous effects (i.e., effect of $\mathrm{X}_{\mathrm{t} 2}$ on $\mathrm{Y}_{\mathrm{t} 2}$ and vice versa). The lack of causal effects might be due to the relatively large time span between the measurements (9 years). Any short-term effect of membership on trust or vice versa would thus be hard to detect (Van Ingen and Bekkers 2015). Using fixed-effects models, Bekkers (2012) shows that changes in volunteering-a much more intense experience than mere membership-do not lead to changes in trust. Van Ingen and Bekkers (2015) - also using fixed-effects models - find that the causal effects of civic engagement on trust were very small (in case of membership) or non-significant 
(in case of volunteering). The small increase in trust by membership also does not seem to last: it disappears after two years. Finally, Sturgis et al. (2012) show that none of their social contact variables, both formal (number of memberships, frequency of attendance) and informal (frequency of meeting friends/relatives, frequency of talking to neighbors), are significant predictors of trust in their fixed-effects models. Taken together, these longitudinal studies, especially the ones that use a fixed-effects approach, show that there is little substantial evidence that social contacts, both informal and formal, stimulate generalized trust. This implies that the results of the cross-sectional studies are subject to unobserved heterogeneity bias.

In reverse, generalized trust is thought to influence the initiating and maintaining social contacts through expectations of cooperation. Tooby et al. (2006) note that cooperative behavior could not have been maintained over evolutionary time if free riders outcompeted contributors to collective enterprises. As a result, humans evolved mechanisms that make them avoid and punish free riding behavior. One of those mechanisms is that of 'conditional operation' - most people cooperate, but only if they have the expectation that others cooperate as well (Pruitt and Kimmel 1977). The more pre-existent trust there is, the more likely it is that an individual has positive expectations that the other will cooperate, and the more likely it is that one forms and maintains social contacts.

Studies, both in the laboratory and the field, consistently show that humans are indeed conditional operators (see review by Gächter 2006) and that generalized trust is associated with more cooperative behavior (Acedo-Carmona and Gomila 2014). As mentioned before, cross-sectional studies generally confirm the presence of a relation between (in)formal social contact and generalized trust. Bekkers (2012) finds in his longitudinal study that the effect of volunteering on generalized trust materializes in the form of a higher likelihood of trusters to start volunteering and a lower likelihood of trusters to quit. Other longitudinal studies find no causal flow from generalized trust to social contact indicators (see previous discussions of Claibourn and Martin 2000; and Glanville et al. 2013).

In the current study, based on the theoretical notion above, and despite of the mixed evidence, we expect our cross-lagged models-accounting for reverse causation bias-to show reciprocal causal relationships between (in)formal social contacts on the one hand and generalize trust on the other, that is: $H 3 a$; the higher the level of informal social contacts the stronger the increase in generalized trust, $H 3 b$; the higher the level of generalized trust, the stronger the increase in informal contacts, H4a; the higher the level of formal social contacts the stronger the increase in generalized trust, and H4b; the higher the level of generalized trust, the stronger the increase in formal social contacts, and we expect our fixed-effects models to indicate these relationships to be free from unobserved heterogeneity bias.

\section{Data, Method and Measurements}

\subsection{The NEtherlands Longitudinal Lifecourse Study}

The current study deploys data from the NEtherlands Longitudinal Lifecourse Study (NELLS), which is a large-scale, longitudinal panel survey focusing on the themes of social cohesion, norms and values (for more details, see Tolsma et al. 2014). The target population consists of Dutch speaking citizens in the Netherlands between 15 and 45 years old. A few respondents were included aged 46-49. We decided not to exclude these respondents. At 
present, two waves have been conducted. The fieldwork of the first wave was performed in 2009 and the first half of 2010. In the first wave, two-stage stratified sampling was applied. The first stage was a quasi-random selection of 35 municipalities by region and urbanization, while the four biggest cities in the Netherlands were added to the sample in a nonrandom manner to obtain a representative sample of Turks and Moroccans. Yet, due to the stratification by region and degree of urbanization, we assume that potential bias in the first stage is (largely) reduced. The second stage was a random selection from the population registry based on age and country of birth of the respondent and his/her parents. We have to keep in mind that there is some selection effect as those immigrants who do not speak Dutch properly, are not included in the survey. Respondents were given a face-to-face interview and a self-completion questionnaire. The net response rate was 52 percent among all respondents. In 2013, the participants of the first wave were approached for a second time. The net response rate for the second wave was 75 percent. In total, 2829 respondents participated in both waves. Initially, some groups were overrepresented (women, the elderly, Southerners and people in moderately urbanized municipalities) while other groups (Turks and Moroccans) were oversampled on purpose. Moreover, there is (selective) panel attrition between both waves, which is related to sex, ethnicity, region and urbanization (for more information, see Tolsma et al. 2014). Yet, as we are interested in (causal) relationships, rather than generalizing univariate descriptive statistics of our sample to the general population, we do not consider this as problematic. For that reason, we also decided not to apply weights but rather included relevant covariates as control variables. Missing values are imputed through an automatic multiple imputation procedure performed in SPSS, version 23, which takes the average of 20 imputations. The maximum percentage of missing values on a variable is $13.2 \%$ (household income). To rule out biased findings with regard to our hypotheses on income and material deprivation, we only selected respondents who are not enrolled in full-time education and who moved out of their parental home, as we expect them to be economically independent. After this selection, the analytic sample consists of 1913 respondents with information for both waves.

\subsection{Measurements}

Many large-scale surveys include the standard question (single item measure) of trust using two anchors ('most people can be trusted' vs. 'one can't be too careful'). Some researchers find this wording troublesome, as 'most people' can refer to either a large group of unknown people, or to a smaller group of network members (e.g. Nannestad 2008), questioning the validity of this measurement. Furthermore, the reliability of the measurement might be problematic, as random errors cannot be detected and dealt with using a single item. The NELLS-panel contains a four-item measurement of generalized trust, asking respondents to what extent they agree with the following statements: 'most people can be trusted', 'you can never be careful enough when dealing with other people', 'if you are too trusting, people will take advantage of you', and 'if you help others, people will play tricks on you'. Answer categories range from 'do not agree at all' to 'agree entirely' on a fivepoint scale. We estimate the face-validity of these items to be high, as the wording of the items strongly coincides with the theoretical notion of the estimated risk that other people will not reciprocate (for instance: "you can never be careful enough", "people will take advantage", and "people will play tricks". After reverse-coding items 2, 3 and 4 (higher scores meaning more trusting), we constructed a scale by taking the mean of the scores on at least three of these items. The Cronbach's $\alpha$ of .724 indicates acceptable reliability 
(Kline 2000: 13), which an exploratory factoranalysis (EFA) furthermore underscores: All items load on one dimension and the communalities are larger than .20 (results available upon request).

Two indicators of financial success are used: household income and material deprivation. To construct our measure of household income, we first considered the midpoint of each class (e.g., €500-€999 is coded as €750). Before we applied this procedure, we grouped the first three categories: 'less than €150', '€150-€299' and '€300-€499'. Next, we applied a so-called 'equivalence scale' (OECD 2009): the net household income per month was divided by the square root of the number of persons in the household. Households with more than six people are capped at six people.

Material deprivation is measured using an additive scale (Cronbach's $\alpha=.741$ ) consisting of five yes (' 1 ')/no ('0') items: 'not being able to replace broken things', 'having to borrow money for emergencies', 'having outstanding bills for rent, mortgage, gas, electric and/or water', 'had visits from debt collectors' and 'having difficulty making ends meet'. This measurement combines basic economic deprivation (the inability to fulfill basic needs) and experienced economic strain (difficulties to make ends meet). These concepts are validated and widely used in research on causes and consequences of poverty (e.g. Whelan et al. 2001), and have a stronger predictive value in terms of, for instance, suffering from bad health and social isolation than poverty measures based on objective income have (Halleröd and Larsson 2008).

Informal contact is measured by taking the average frequency of face-to-face contact an individual has with his or her (i) family members (largely not belonging to the respondents' household, such as siblings, aunts and uncles and grandparents), (ii) friends, (iii) colleagues/fellow students (outside work/school), and (iv) neighbors. Answer categories range from 'never' to '(almost) daily' on a seven-point scale, as well as the option 'not applicable (do not have this person)'. When calculating the average contact frequency, we excluded categories which are not applicable. Respondents answering 'not applicable' to all four items, were treated as 'never' having contact. Higher scores on our measure of informal contact refer to a higher frequency of contact. These items are (partly) mutually exclusive due to reasons of time displacement: respondents who regularly interact with, for instance, friends might have less opportunities for frequent interactions with family and vice versa. As such we do not consider these items of informal social capital as repeated measures of one single concept, and calculating reliability measures would not be useful. Nevertheless, we estimate the validity of the construct to be sufficiently high. Compared to non-face-toface situations, face-to-face contact is more important in building trust, because it enables the communication of complex knowledge and sharing of discourses, meanings and norms (Nilsson and Mattes 2015). It also facilitates greater social information exchange, therefore leading to more rapid creation of trust (Turner, 2002). If effects are to be found, the easiest way to locate them would therefore be by looking at face-to-face communication. As such, each informal contact is valuable and the higher the frequency of informal contact, the stronger its consequences.

A similar argument can be made for formal contact. Previous research argued that generalized trust can emerge more easily if people are more actively involved in formal networks, for instance, having frequent face-to-face contacts in addition to merely donating money (Sønderskov 2011; Van Ingen and Bekkers 2015; Wollebaek and Selle 2002). We presume that respondents are likely to have face-to-face contacts in the following types of organizations: (i) leisure organizations (hobby, music or culture); (ii) sport association (club, commercial provider, or other association); (iii) neighborhood, district or tenant organization; (iv) immigrant-serving organizations; and (v) religious organizations. Our 
measure of formal contact refers to the number of different types of organizations respondents are a member of and ranges from 0 to 5 . We propose that the more different organizations one is involved in, the more likely it is to come in contact with people who are dissimilar to oneself, and thus the easier it is to gain a sense that people, who in general are diverse and unknown, are to be trusted.

Changes in generalized trust may be linked to other (changes in) individual characteristics that may also be related to changes in financial success and (in)formal contact (see Nannestad 2008 for a review of causes and consequences of trust). In order to provide accurate estimates, it is thus necessary to control for the influences of these confounders. In both our cross-lagged models and fixed-effects models, we control for age, education, religious attendance, household composition and traumatic experiences. Education is measured by the minimum years needed to complete the highest attained educational level. We use a dichotomous variable to capture religious attendance, considering whether or not the respondent attends religious activities at least once per month. We included the respondents' household composition, differentiating between 'pair without children', 'pair with children', 'single parent', 'single' (reference category), and 'otherwise'. Traumatic and negative experiences, such as the loss of a partner or becoming a victim of crime, are expected to diminish both social interaction and trust. To control for the influence of partner-related issues, a dichotomous variable is added to the models that indicates whether or not the respondent has ever become separated from, divorced, or lost his or her partner. To control for the influence of victimization, a dichotomous variable is added that indicates whether or not the respondent has become victim to one or more of the following crimes within the past twelve months: burglary; intentional property damage; pickpocketing; robbery; physical assault; and threatened assault.

In our cross-lagged models, we additionally control for sex (male is coded as reference) and ethnicity. Ethnicity is measured applying the general definition of Statistics Netherlands: if the self-reported country of birth of the respondent and/or of at least one of the parents is not the Netherlands, then the respondent is considered to be a non-native (1), which in our sample are mostly first and second generation Turks and Moroccans. Otherwise, he or she is considered to be a native (0). It is not necessary to include these timeinvariant controls in our fixed-effects models, as these analyses partial out the influences of all observed and unobserved time-invariant characteristics of individuals. Descriptive statistics of all variables are shown in Table 1. Although differences between both waves are - on average - rather small, this does not imply that individual respondents remain stable in their level of trust, financial success and/or (in)formal social contact.

\section{Method}

We start with estimating two-wave cross-lagged panel models (Finkel 2008) through maximum likelihood in LISREL 8.8 (Jöreskog and Sörbom 2006). Reciprocal relations are estimated for the effects of generalized trust on the one hand and financial success and (in)formal social contacts on the other hand (and vice versa), while controlling for sex, ethnicity, age, education, household composition, religious attendance and traumatic experiences. We start with estimating models that only include generalized trust and one key variable of interest (e.g., household income or material deprivation) next to our controls (Table 2). Subsequently, we conduct analyses including all social phenomena of interest simultaneously for a more strict test of our hypotheses and to assess the 
Table 1 Descriptive statistics $(\mathrm{N}=1913)$

\begin{tabular}{|c|c|c|c|c|c|c|}
\hline & \multicolumn{3}{|l|}{ Wave 1} & \multicolumn{3}{|l|}{ Wave 2} \\
\hline & Mean & Std. Dev. & Range & Mean & Std. Dev. & Range \\
\hline \multicolumn{7}{|l|}{ (In)dependent variables } \\
\hline Generalized trust & 3.13 & 0.65 & $1-5$ & 3.15 & 0.68 & $1-5$ \\
\hline Household income & 1562.38 & 782.23 & $250-7250$ & 1549.90 & 788.12 & $250-7250$ \\
\hline Material deprivation & 0.63 & 1.11 & $0-5$ & 0.69 & 1.84 & $0-5$ \\
\hline Informal social contacts & 3.72 & 1.02 & $1-7$ & 3.71 & 1.02 & $1-7$ \\
\hline Formal social contacts & 0.83 & 0.86 & $0-5$ & 0.82 & 0.86 & $0-5$ \\
\hline \multicolumn{7}{|l|}{ Controls } \\
\hline Age & 36.31 & 6.04 & $17-49$ & 39.99 & 6.00 & $22-53$ \\
\hline Religious attendance & 0.18 & & $0 / 1$ & 0.19 & & $0 / 1$ \\
\hline Victimization & 0.23 & & $0 / 1$ & 0.21 & & $0 / 1$ \\
\hline Divorced/widow(er) & 0.18 & & $0 / 1$ & 0.08 & & $0 / 1$ \\
\hline Sex $(\text { ref. }=\text { male })^{\mathrm{a}}$ & 0.56 & & $0 / 1$ & & & $0 / 1$ \\
\hline Ethnicity $(\text { ref. }=\text { native })^{\mathrm{a}}$ & 0.38 & & $0 / 1$ & & & $0 / 1$ \\
\hline Educational attainment & 14.24 & 3.31 & $0-21$ & 14.52 & 2.97 & $0-21$ \\
\hline \multicolumn{7}{|l|}{ House composition } \\
\hline Single parent & 0.07 & & $0 / 1$ & 0.07 & & $0 / 1$ \\
\hline Pair without children & 0.18 & & $0 / 1$ & 0.11 & & $0 / 1$ \\
\hline Pair with children & 0.64 & & $0 / 1$ & 0.69 & & $0 / 1$ \\
\hline Otherwise & 0.10 & & $0 / 1$ & 0.05 & & $0 / 1$ \\
\hline Single (ref.) & 0.01 & & $0 / 1$ & 0.08 & & $0 / 1$ \\
\hline
\end{tabular}

Source: NEtherlands Longitudinal Lifecourse Study (NELLS)

a Only included in cross-lagged panel models

unique contribution of each indicator (Table 3). We also included correlations between generalized trust and our key variables at $\mathrm{t} 1$, as well as correlations between the disturbance terms of generalized trust and our key variables at $\mathrm{t} 2$ (results available upon request). As in all models all parameters are estimated, they are fully saturated and thus have perfect fit (i.e., $\chi^{2}=0, \mathrm{CFI}=1$, RMSEA $=0$ ). Since the hypotheses state a direction of interest, one-tailed tests are used to determine statistical significance.

Additionally we estimate fixed-effects models (Allison 2005b) using Stata version 13. We conducted a Hausman-test to indicate whether the assumption that the unobserved heterogeneity is correlated with the independent variables is correct or not, and therefore whether a fixed-effects or random-effects model is appropriate. The results indicate that the fixed-effects model is preferred over the random-effects model. Fixed effect models partial out influences of all observed and unobserved time-invariant characteristics of individuals, confounding or not. If we do find correlations between our variables of interest, we can rule out that they are spurious due to, for instance, unobserved personality traits. Additionally, we partial out influences of the following timevariant characteristics: Age, education, religious attendance, traumatic experiences and household composition. For both the cross-lagged models and fixed-effects models, we present standardized coefficients. Formal equations of our models can be found in "Appendix 1". 
Table 2 Results cross-lagged panel models and fixed effects models_-'bivariate' models $(\mathrm{N}=1913)$

\begin{tabular}{|c|c|c|c|c|c|c|c|c|c|c|}
\hline \multirow{2}{*}{$\begin{array}{l}\text { Wave } 2 \\
\text { Wave } 1\end{array}$} & \multicolumn{2}{|c|}{ Generalized trust } & \multicolumn{2}{|c|}{$\begin{array}{l}\text { Household } \\
\text { income }\end{array}$} & \multicolumn{2}{|c|}{$\begin{array}{l}\text { Material depri- } \\
\text { vation }\end{array}$} & \multicolumn{2}{|c|}{$\begin{array}{l}\text { Informal } \\
\text { social con- } \\
\text { tacts }\end{array}$} & \multicolumn{2}{|c|}{$\begin{array}{l}\text { Formal } \\
\text { social con- } \\
\text { tacts }\end{array}$} \\
\hline & Beta & $T$ & Beta & $T$ & Beta & $T$ & Beta & $T$ & Beta & $T$ \\
\hline \multicolumn{11}{|l|}{ Cross-lagged } \\
\hline Generalized trust & & & $.03 *$ & 1.97 & $-.09 * *$ & -4.30 & -.01 & -.52 & $.04 * *$ & 2.05 \\
\hline Household income & $.06^{* *}$ & 2.55 & & & & & & & & \\
\hline Material deprivation & -.02 & -1.15 & & & & & & & & \\
\hline Informal social contacts & -.01 & -.52 & & & & & & & & \\
\hline Formal social contacts & $.04 * *$ & 2.49 & & & & & & & & \\
\hline \multicolumn{11}{|l|}{ Fixed-effects } \\
\hline Generalized trust & & & $.04 *$ & 2.32 & $-.09 * *$ & -3.30 & -.01 & -.22 & -.01 & -.34 \\
\hline Household income & $.06^{*}$ & 2.32 & & & & & & & & \\
\hline Material deprivation & $-.07 * *$ & -3.30 & & & & & & & & \\
\hline Informal social contacts & -.00 & -.22 & & & & & & & & \\
\hline Formal social contacts & -.00 & -.34 & & & & & & & & \\
\hline
\end{tabular}

Source: NEtherlands Longitudinal Lifecourse Study (NELLS). $* * P<.01 ; * P<.05$ (one-tailed test of significance)

All models are controlled for age, education, religious attendance, traumatic experiences and household composition (for cross-lagged models only at $\mathrm{t} 1$ ), while our cross-lagged models additionally include sex and ethnicity (results available upon request)

Table 3 Results cross-lagged panel models and fixed effects models-full models $(\mathrm{N}=1913)$

\begin{tabular}{|c|c|c|c|c|c|c|c|c|c|c|}
\hline \multirow{2}{*}{$\begin{array}{l}\text { Wave } 2 \\
\text { Wave } 1\end{array}$} & \multicolumn{2}{|c|}{$\begin{array}{l}\text { Generalized } \\
\text { trust }\end{array}$} & \multicolumn{2}{|c|}{$\begin{array}{l}\text { Household } \\
\text { income }\end{array}$} & \multicolumn{2}{|c|}{$\begin{array}{l}\text { Material depri- } \\
\text { vation }\end{array}$} & \multicolumn{2}{|c|}{$\begin{array}{l}\text { Informal } \\
\text { social con- } \\
\text { tacts }\end{array}$} & \multicolumn{2}{|c|}{$\begin{array}{l}\text { Formal } \\
\text { social con- } \\
\text { tacts }\end{array}$} \\
\hline & Beta & $T$ & Beta & $T$ & Beta & $T$ & Beta & $T$ & Beta & $T$ \\
\hline \multicolumn{11}{|l|}{ Cross-lagged } \\
\hline Generalized trust & & & $.04 * *$ & 2.73 & $-.08 * *$ & -3.64 & .02 & 1.09 & $.05^{*}$ & 2.15 \\
\hline Household income & $.09 * *$ & 3.91 & & & & & & & & \\
\hline Material deprivation & -.01 & -.28 & & & & & & & & \\
\hline Informal social contacts & -.02 & -0.96 & & & & & & & & \\
\hline Formal social contacts & $.05 * *$ & 2.59 & & & & & & & & \\
\hline \multicolumn{11}{|l|}{ Fixed-effects } \\
\hline Generalized trust & & & $.04^{*}$ & 1.95 & $-.08 * *$ & -3.05 & -.02 & -.11 & -.01 & -.29 \\
\hline Household income & $.05 *$ & 1.95 & & & & & & & & \\
\hline Material deprivation & $-.06 * *$ & -3.05 & & & & & & & & \\
\hline Informal social contacts & -.00 & -.11 & & & & & & & & \\
\hline Formal social contacts & -.01 & -.29 & & & & & & & & \\
\hline
\end{tabular}

Source: NEtherlands Longitudinal Lifecourse Study (NELLS). $* * P<.01 ; * P<.05$ (one-tailed test of significance)

All models are controlled for age, education, religious attendance, traumatic experiences and household composition (for cross-lagged models only at $\mathrm{t} 1$ ) while our cross-lagged models additionally include sex and ethnicity (results available upon request). Moreover all key variables are included simultaneously 


\section{Results}

Table 2 summarizes the findings from the 'bivariate' cross-lagged models and fixedeffects models, including generalized trust and our key variables one by one, next to our controls. Results from our cross-lagged models-ruling out reciprocal causation biasclearly show that higher levels of household income at timepoint 1 are associated with an increase in generalized trust $(\beta=.06, p<.01)$ corroborating hypothesis $1 \mathrm{a}$. We also find support for the reversed causal relationship: higher levels of trust at timepoint 1 are associated with an increase in household income $(\beta=.03, p<.05)$. Although the effect is smaller, this is in line with hypothesis $1 \mathrm{~b}$. As is indicated by our findings from the fixed-effects models, we still find support for a relationship between household income and generalized trust (and vice versa) if we rule out unobserved heterogeneity $(\beta=.06$ and $.04, p<.05$ respectively). In sum, we find a reciprocal causal-two-way streetrelationship between generalized trust and household income, which according to our fixed effects models does not suffer from unobserved heterogeneity.

For our other key indicator of financial success, i.e., material deprivation, we reach a dissimilar conclusion. Our cross-lagged panel model shows that a higher level of material deprivation at timepoint 1 does not decrease (nor increase) generalized trust between timepoint 1 and 2 ( $\beta=-.02$, n.s.). Hypothesis $2 \mathrm{a}$ is not corroborated. Even though in the fixed-effects model increases in material deprivation significantly decreases generalized trust $(\beta=-.07, p<.01)$, this is likely due to reverse causation bias. Clearly, the crosslagged panel model does show this reverse path (which is not accounted for in the fixedeffects model): the higher generalized trust is at timepoint 1 , the stronger the decrease in material deprivation between timepoint 1 and $2(\beta=-.09, p<.01)$. This latter finding is in line with hypothesis $2 \mathrm{~b}$. Since in the fixed-effects model an increase in generalized trust is also associated with a significant decrease in material deprivation $((\beta=-.09$, $p<.01)$, we can quite safely assume that the cross-lagged path from trust at timepoint 1 to material deprivation at timepoint 2 does not suffer from unobserved heterogeneity bias. To sum up: Material deprivation and generalized trust are a one-way street; more trusting individuals experience less material deprivation, but material deprivation does not causally influence trust.

For our indicators of social contacts, both informal and formal, we can be brief: All related hypotheses $(3 \mathrm{a}, 3 \mathrm{~b}, 4 \mathrm{a}$, and $4 \mathrm{~b})$ have to be rejected. There are no significant paths in our cross-lagged panel models between trust and informal social contacts. Furthermore, the fixed-effects models show that changes in informal social contacts are not related to changes in generalized trust, and vice versa. For formal social contact, we do find significant paths to and from generalized trust in the cross-lagged panel model, but the insignificant relations found in the fixed-effects models indicate that they are likely biased due to unobserved heterogeneity. In sum, according to our models, trust and social contacts, informal and formal, are a dead-end street.

Similar conclusions arise if we include the other key indicators in our models (Table 3: full models), in which mediating processes are accounted for (for instance: higher trust levels cause a decrease in material deprivation, because the more trusting one is, the stronger the increase in income). Coefficients hardly change, and if they do, they actually become a bit stronger. Furthermore, conclusions remain similar if we exclude membership of immigrant organizations - which may be particularly relevant for non-natives and therefore possibly introduces a bias-from our measure of formal social contacts (results available upon request). 


\section{Conclusion and Discussion}

As generalized trust is linked to various benefits on an individual and societal level, it does not come as a surprise that there is a large body of research addressing the causes and consequences of generalized trust (for a review of studies, see, for instance, Nannestad 2008). Despite this large amount of research, generalized trust is not well understood. Scholars disagree whether and to what extent generalized trust should be considered as a fixed personality trait or as an individual characteristic influenced by individual adult life experiences (e.g., Uslaner 2002; Glanville and Paxton 2007). Studies following the latter line of reasoning, generally suffer from an unresolved matter of causality. As Delhey and Newton (2003) point out, most empirical findings face a severe chicken-and-egg problem, as generalized trust is likely to operate both as a cause and an effect.

The vast majority of studies on relationships between generalized trust and social phenomena like financial success or (in)formal contacts is based on cross-sectional data (e.g., Brehm and Rahn 1997; Delhey and Newton 2003; Paxton 2007). Because this kind of studies is unable to take into account reversed causality, findings suffer from reciprocal causation bias. Moreover, these studies lack a correction of unobserved heterogeneity bias, caused by unaccounted differences in, for instance, sociability. In recent years, scholars started to assess the relationship between generalized trust and various social phenomena more accurately, employing longitudinal panel data. The majority of longitudinal studies used fixed-effects models, correcting for unobserved heterogeneity bias (e.g., Sturgis et al. 2012; Van Ingen and Bekkers 2015), but are unable to consider reversed causality. As far as we know, only three studies conducted cross-lagged panel models to rule out reciprocal causation bias (Claibourn and Martin 2000; Glanville et al. 2013; Brandt et al. 2015). Yet, these studies cannot rule out any unobserved heterogeneity. Only Glanville and colleagues (2013) combined both methods.

This contribution intended to provide an overview and a better understanding of reciprocal causal relations between generalized trust on the one hand and financial success and social contact on the other. Using panel data from the NEtherlands Longitudinal Lifecourse Study (NELLS), we combined insights from both cross-lagged panel analyses and fixedeffects models to correct for unobserved heterogeneity bias and reciprocal causation bias. Unlike previous research, we tested our models more rigorously by taking into account all indicators of financial success and social contacts simultaneously, enabling us to assess the unique contribution of each indicator.

Focusing on relationships between generalized trust and a broad range of social phenomena, for household income we were able to reach very consistent conclusions: we find clear support for causal relationships with generalized trust and vice versa, which are not spurious due to unaccounted differences in, for instance, personality traits. In line with earlier longitudinal research utilizing cross-lagged models (Brandt et al. 2015), we find that a higher income causally predicts an increase in generalized trust. This is in line with our expectation that successful people tend to trust more than the unsuccessful, because they can better cope with the negative consequences of non-reciprocation (e.g., Delhey and Newton 2003). In addition, we find clear support for a reversed causal relationship. We expected that generalized trust would increase household income through the resources one can borrow from those who one is willing to trust (Lin 2001, 2005; Putnam 2000). Indeed, higher levels of generalized trust are related with increases in household income. This finding contradicts results from Brandt et al. (2015), who only find a causal relationship from income with generalized trust in their cross-lagged panel models. Note, however, that 
their approach is slightly different as they assessed causal relationships between changes in income and trust between wave 1 and wave 2 on changes in these concepts between wave 2 and wave 3. Moreover, they focus on the general populations of the United States and the United Kingdom. It is possible that the income of younger people (in our study, the average age was 36) is more likely to be influenced by levels of generalized trust as compared to older people. Hence, future research could assess whether causal relationship differ across countries or age groups. To summarize, there is compelling evidence that generalized trust and household income function as a two-way street, which is a novel finding in this research field.

The findings for material deprivation partly substantiate this claim. Material deprivations seems to be unrelated to changes in trust, yet more trusting individuals experience a stronger decrease in material deprivation. Here a one-way street from trust to material deprivation is found, again suggesting that trust opens doors to network resources to alleviate the burden of a lack of financial resources (Lin 2001, 2005; Putnam 2000). Focusing on both household income and material deprivation, we were able to assess the concept of financial success more broadly as compared to earlier longitudinal research on causes and consequences of generalized trust (e.g., Brandt et al. 2015), while assessing the individual impact of both dimensions of financial success on trust.

As compared to our findings for financial success, the picture regarding social contacts is completely different. Social contacts, both formal and informal, were thought to encourage the development of generalized trust through ongoing social interactions with network members (Delhey and Newton 2003; Putnam 2000). In reverse, generalized trust was expected to influence the initiating and maintaining of social contacts through expectations of cooperative behavior (Pruitt and Kimmel 1977). In line with Sturgis and colleagues' (2012) conclusions based on fixed-effects models but contrary to Glanville and colleagues' (2013) cross-lagged panel results, we find no causal relationships between informal social contacts and generalized trust (or vice versa), indicating a dead-end street. Our findings lend no support to the idea that ongoing social experiences within one's core social contacts produce trust.

Results from our cross-lagged models indicate that generalized trust seems to be both a cause and a consequence of formal social capital. This is at odds with Claibourn and Martin's (2000) findings based on cross-lagged panel models. These differences in results may very well lie in which variables were used to indicate formal social contact. While Claibourn and Martin (2000) relied on group membership as an indicator of formal social contact, we focused on a more intense experience, namely membership of (voluntary) organizations in which face-to-face contact is highly likely. These disparities give credence to the idea that generalized trust is only influenced by active, not passive, forms of group membership (Sønderskov 2011; Van Ingen and Bekkers 2015; Wollebaek and Selle 2002). However, once we correct for unobserved heterogeneity bias in our fixed-effects models, generalized trust and formal social contacts are no longer causally related, once more indicating a dead-end street. This supports conclusions from earlier longitudinal research employing fixed-effects models (Bekkers 2012; Sturgis et al. 2012; Van Ingen and Bekkers 2015) and substantiates the idea that relationships between formal social contacts and generalized trust might be due to unobserved differences in sociability, i.e., a 'joiner nature' (Glanville et al. 2013; Stolle 2001; Sturgis et al. 2012).

Although these findings yield valuable insights into the effects of financial success and social contact on generalized trust and vice versa, there are some methodological shortcomings of the current study that need to be discussed. A first shortcoming is that no alternative lag specifications were considered, which might dampen the effects that 
were found. The cross-lagged panel model assumes that the time lag necessary for $\mathrm{X}_{\mathrm{t} 1}$ to influence $\mathrm{Y}_{\mathrm{t} 2}$ is sufficiently long but still shorter than the time elapsed between the panel waves (Finkel, 1995). However, if the causal lag for $\mathrm{X}$ to influence $\mathrm{Y}$ is (very) short, relative to the time elapsed between waves of measurement, then a synchronous effects model is more appropriate (i.e., effects of $\mathrm{X}_{\mathrm{t} 2}$ on $\mathrm{Y}_{\mathrm{t} 2}$ and vice versa). Of course, theoretical notions might also support the choice for a model that includes both crosslagged and synchronous effects. Specifying synchronous paths can be rather challenging, since 'instrumental variables' (that predict $\mathrm{X}_{\mathrm{t} 2}$ but not $\mathrm{Y}_{\mathrm{t} 2}$; and vice versa) need to be included in the model for it to identify, while such variables are theoretically hard to come by. Yet, the inclusion in our cross-lagged panel models of time-(in)variant control variables, as well as broader set of financial and social indicators, decreases the likelihood of (strong) synchronous effects being existent. Nevertheless, future studies should experiment with alternative lag and model specifications to check whether conclusions change substantively under such conditions.

Another methodological shortcoming is the lack of correction for unobserved heterogeneity bias and reciprocal causation bias simultaneously. Although this contribution builds on earlier research by drawing conclusions based on findings from both crosslagged panel models and fixed-effects models, we had to rely on less-than-ideal, separate analyses (cf. Glanville et al. 2013; Sønderskov and Dinesen 2016). Advancements in the scientific field have made it possible to combine the cross-lagged model with fixed-effects estimation (for a discussion, see e.g., Allison 2005a; Finkel 2008). Yet a minimum of three (and preferably four) waves is required to apply such methods, and information rich, high quality data is scarce. Future studies with richer data could experiment with these new methods thus providing better protection against different types of biases. Longitudinal data with more than two waves are also needed to assess indirect relationships more accurately. Generalized trust might, for instance, induce financial success via increased social contacts (Putnam 2000). As we only had two waves at our disposal, we were unable to take this and other indirect relationships into account. Yet, in our models we controlled for relevant indicators reflecting indirect relationships.

Summarizing, in this contribution we assessed causal relationships between generalized trust and a broad range of social phenomena, while correcting for unobserved heterogeneity bias and reversed causality bias. Overall, we conclude that for household income compelling empirical evidence has been found that reciprocal, unbiased relationships exist with generalized trust, and that trusting individuals are better able to concur material deprivation. Yet for (in)formal social contact we conclude that for the Dutch NELLS-panel, our models strongly suggest that causal relationships to and from trust are inexistent.

\section{Appendix 1: Equations}

\section{Cross Lagged Panel Model (Finkel 1995)}

$$
\begin{aligned}
& \mathrm{X}_{\mathrm{t} 2}=\beta 3 * \mathrm{Y}_{\mathrm{t} 1}+\beta 2 * \mathrm{X}_{\mathrm{t} 1}+\beta 5 * \text { Covariate }_{\mathrm{t} 1}+\mathrm{U} 2 \\
& \mathrm{Y}_{\mathrm{t} 2}=\beta 4 * \mathrm{Y}_{\mathrm{t} 1}+\beta 1 * \mathrm{X}_{\mathrm{t} 1}+\beta 6 * \text { Covariate }_{\mathrm{t} 1}+\mathrm{U} 1
\end{aligned}
$$




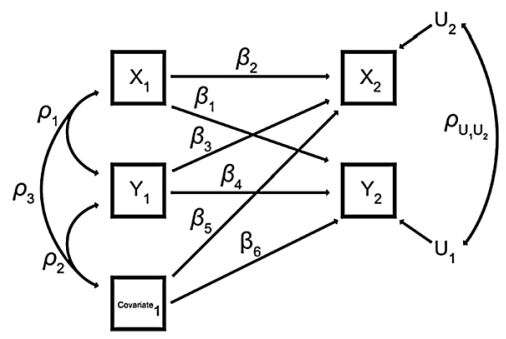

where

- all variables in the model are expressed in mean deviation form to eliminate consideration of the intercept term

- $\mathrm{X}_{\mathrm{t} 2}$ and $\mathrm{Y}_{\mathrm{t} 2}$ are determined by their wave 1 values, the lagged value of the other variable, covariates at $\mathrm{t} 1$ and an error term $\mathrm{U}$

- The correlation between wave 1 variables is represented by rho.

- The correlation between structural disturbance terms is represented by rhoU1U2.

\section{'Bivariate' Cross Lagged Panel Model (Household Income)}

Ytrust $_{\mathrm{t} 2}=\beta 1 *$ Ytrust $_{\mathrm{t} 1}+\beta 2 *$ Xhouseholdincome $_{\mathrm{t} 1}+\beta 3 * \mathrm{Xsex}_{\mathrm{t} 1}+\beta 4 *$ Xage $_{\mathrm{t} 1}+\beta 5 *$ Xeducation $_{\mathrm{t} 1}+\beta 6 *$ Xethnic $_{\mathrm{t} 1}$

$+\beta 7 *$ Xreligionattendance $_{\mathrm{t} 1}+\beta 8 *$ Xvictimhood $_{\mathrm{t} 1}+\beta 9 *$ Xpartnerproblems $_{\mathrm{t} 1}$

$+\beta 10 *$ Xhouseholdcompositiondummy $1_{\mathrm{t} 1}+\beta 11 *$ Xhouseholdcompositiondummy $2_{\mathrm{t} 1}$

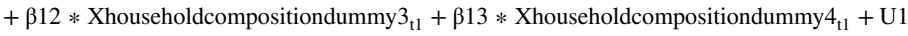

Xhouseholdincome $_{\mathrm{t} 2}=\beta 1 *$ Ytrust $_{\mathrm{t} 1}+\beta 2 *$ Xhouseholdincome $_{\mathrm{t} 1}+\beta 3 * \mathrm{Xsex}_{\mathrm{t} 1}+\beta 4 *$ Xage $_{\mathrm{t} 1}+\beta 5 *$ Xeducation $_{t 1}$ $+\beta 6 *$ Xethnic $_{\mathrm{t} 1}+\beta 7 *$ Xreligionattendance $_{\mathrm{t} 1}+\beta 8 *$ Xvictimhood $_{\mathrm{t} 1}+\beta 9 *$ Xpartnerproblems $_{\mathrm{t} 1}$

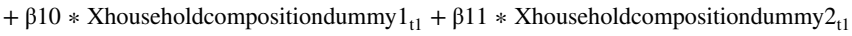

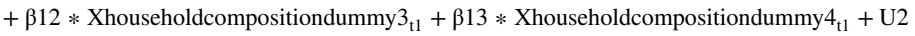

\section{'Bivariate' Cross Lagged Panel Model (Material Deprivation)}

Ytrust $_{\mathrm{t} 2}=\beta 1 *$ Ytrust $_{\mathrm{t} 1}+\beta 2 *$ Xmaterialdeprivation $_{\mathrm{t} 1}+\beta 3 * \mathrm{Xsex}_{\mathrm{t} 1}+\beta 4 * \mathrm{Xage}_{\mathrm{t} 1}+\beta 5 *$ Xeducation $_{\mathrm{t} 1}+\beta 6 *$ Xethnic $_{\mathrm{t} 1}$

$+\beta 7 *$ Xreligionattendance $_{\mathrm{t} 1}+\beta 8 *$ Xvictimhood $_{\mathrm{t} 1}+\beta 9 *$ Xpartnerproblems $_{\mathrm{t} 1}$

$+\beta 10 *$ Xhouseholdcompositiondummy $1_{\mathrm{t} 1}+\beta 11 *$ Xhouseholdcompositiondummy $2_{\mathrm{t} 1}$

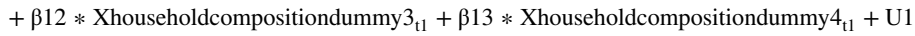

Xmaterialdeprivation $_{\mathrm{t} 2}=\beta 1 *$ Ytrust $_{\mathrm{t} 1}+\beta 2 *$ Xmaterialdeprivation $_{\mathrm{t} 1}+\beta 3 * \mathrm{Xsex}_{\mathrm{t} 1}+\beta 4 * \mathrm{Xage}_{\mathrm{t} 1}+\beta 5 *$ Xeducation $_{\mathrm{t} 1}$ $+\beta 6 *$ Xethnic $_{\mathrm{t} 1}+\beta 7 *$ Xreligionattendance $_{\mathrm{t} 1}+\beta 8 *$ Xvictimhood $_{\mathrm{t} 1}+\beta 9 *$ Xpartnerproblems $_{\mathrm{t} 1}$

$+\beta 10 *$ Xhouseholdcompositiondummy $1_{\mathrm{t} 1}+\beta 11 *$ Xhouseholdcompositiondummy $2_{\mathrm{t} 1}$

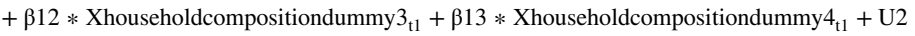




\section{'Bivariate' Cross Lagged Panel Model (Informal Contact)}

Ytrust $_{\mathrm{t} 2}=\beta 1 *$ Ytrust $_{\mathrm{t} 1}+\beta 2 *$ Xinformalcontact $_{\mathrm{t} 1}+\beta 3 *$ Xsex $_{\mathrm{t} 1}+\beta 4 *$ Xage $_{\mathrm{t} 1}+\beta 5 *$ Xeducation $_{\mathrm{t} 1}$

$+\beta 6 *$ Xethnic $_{\mathrm{t} 1}+\beta 7 *$ Xreligionattendance $_{\mathrm{t} 1}+\beta 8 *$ Xvictimhood $_{\mathrm{t} 1}+\beta 9 *$ Xpartnerproblems $_{\mathrm{t} 1}$

$+\beta 10 *$ Xhouseholdcompositiondummy $1_{\mathrm{t} 1}+\beta 11 *$ Xhouseholdcompositiondummy $2_{\mathrm{t} 1}$

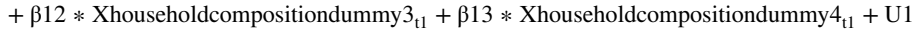

Xinformalcontact $_{\mathrm{t} 2}=\beta 1 *$ Ytrust $_{\mathrm{t} 1}+\beta 2 *$ Xinformalcontact $_{\mathrm{t} 1}+\beta 3 *$ XseX $_{\mathrm{t} 1}+\beta 4 *$ Xage $_{\mathrm{t} 1}+\beta 5 *$ Xeducation $_{\mathrm{t} 1}$ $+\beta 6 *$ Xethnic $_{\mathrm{t} 1}+\beta 7 *$ Xreligionattendance $_{\mathrm{t} 1}+\beta 8 *$ Xvictimhood $_{\mathrm{t} 1}+\beta 9 *$ Xpartnerproblems $_{\mathrm{t} 1}$

$+\beta 10 *$ Xhouseholdcompositiondummy $1_{\mathrm{t} 1}+\beta 11 *$ Xhouseholdcompositiondummy $2_{\mathrm{t} 1}$

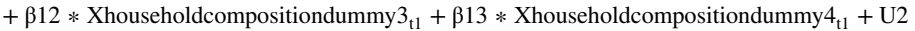

\section{‘Bivariate' Cross Lagged Panel Model (Formal Contact)}

Ytrust $_{\mathrm{t} 2}=\beta 1 *$ Ytrust $_{\mathrm{t} 1}+\beta 2 *$ Xformalcontact $_{\mathrm{t} 1}+\beta 3 *$ Xsex $_{t 1}+\beta 4 *$ Xage $_{\mathrm{t} 1}+\beta 5 *$ Xeducation $_{\mathrm{t} 1}+\beta 6 *$ Xethnic $_{t 1}$

$+\beta 7 *$ Xreligionattendance $_{\mathrm{t} 1}+\beta 8 *$ Xvictimhood $_{\mathrm{t} 1}+\beta 9 *$ Xpartnerproblems $_{\mathrm{t} 1}$

$+\beta 10 *$ Xhouseholdcompositiondummy $1_{\mathrm{t} 1}+\beta 11 *$ Xhouseholdcompositiondummy $2_{\mathrm{t} 1}$

$+\beta 12 *$ Xhouseholdcompositiondummy $3_{\mathrm{t} 1}+\beta 13 *$ Xhouseholdcompositiondummy $4_{\mathrm{t} 1}+\mathrm{U} 1$

Xformalcontact $_{12}=\beta 1 *$ Ytrust $_{\mathrm{t} 1}+\beta 2 *$ Xformalcontact $_{\mathrm{t} 1}+\beta 3 *$ Xsex $_{\mathrm{t} 1}+\beta 4 *$ Xage $_{\mathrm{t} 1}+\beta 5 *$ Xeducation $_{\mathrm{t} 1}+\beta 6 *$ Xethnic $_{\mathrm{t} 1}$

$+\beta 7 *$ Xreligionattendance $_{\mathrm{t} 1}+\beta 8 *$ Xvictimhood $_{\mathrm{t} 1}+\beta 9 *$ Xpartnerproblems $_{\mathrm{t} 1}$

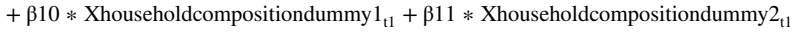

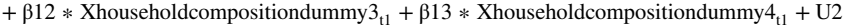

\section{Full Cross Lagged Panel Model}

Ytrust $_{\mathrm{t} 2}=\beta 1 *$ Ytrust $_{\mathrm{t} 1}+\beta 2 *$ Xhouseholdincome $_{\mathrm{t} 1}+\beta 3 *$ Xmaterialdeprivation $_{\mathrm{t} 1}+\beta 4 *$ Xinformalcontact $_{\mathrm{t} 1}$

$+\beta 5 *$ Xformalcontact $_{\mathrm{t} 1}+\beta 6 * \mathrm{Xsex}_{\mathrm{t} 1}+\beta 7 * \mathrm{Xsex}_{\mathrm{t} 1}+\beta 8 * \mathrm{Xsex}_{t 1}+\beta 9 * \mathrm{Xage}_{\mathrm{t} 1}+\beta 10 * \mathrm{Xeducation}_{\mathrm{t} 1}+\beta 11 * \mathrm{Xethnic}_{\mathrm{t} 1}$

$+\beta 12 *$ Xreligionattendance $_{\mathrm{t} 1}+\beta 13 *$ Xvictimhood $_{\mathrm{t} 1}+\beta 14 *$ X partnerproblems $_{\mathrm{t} 1}$

$+\beta 15 *$ Xhouseholdcompositiondummy $1_{\mathrm{t} 1}+\beta 16 *$ Xhouseholdcompositiondummy $2_{\mathrm{t} 1}$

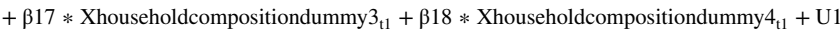

Xhouseholdincome $_{\mathrm{t} 2}=\beta 1 *$ Ytrust $_{\mathrm{t} 1}+\beta 2 *$ Xhouseholdincome $_{\mathrm{t} 1}+\beta 3 *$ Xmaterialdeprivation $_{\mathrm{t} 1}$

$+\beta 4 *$ Xinformalcontact $_{\mathrm{t} 1}+\beta 5 *$ Xformalcontact $_{\mathrm{t} 1}+\beta 6 * \mathrm{Xsex}_{\mathrm{t} 1}+\beta 7 * \mathrm{Xsex}_{\mathrm{t} 1}+\beta 8 * \mathrm{Xsex}_{\mathrm{t} 1}+\beta 9 * \mathrm{Xage}_{\mathrm{t} 1}$

$+\beta 10 *$ Xeducation $_{\mathrm{t} 1}+\beta 11 *$ Xethnic $_{\mathrm{t} 1}+\beta 12 *$ Xreligionattendance $_{\mathrm{t} 1}+\beta 13 *$ Xvictimhood $_{\mathrm{t} 1}+\beta 14 *$ Xpartnerproblems $_{\mathrm{t} 1}$

$+\beta 15 *$ Xhouseholdcompositiondummy $1_{\mathrm{t} 1}+\beta 16 *$ Xhouseholdcompositiondummy $2_{\mathrm{t} 1}$

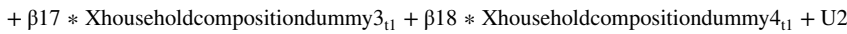


Xmaterialdeprivation $_{\mathrm{t} 2}=\beta 1 *$ Ytrust $_{\mathrm{t} 1}+\beta 2 *$ Xhouseholdincome $_{\mathrm{t} 1}+\beta 3 *$ Xmaterialdeprivation $_{\mathrm{t} 1}$

$+\beta 4 *$ Xinformalcontact $_{\mathrm{t} 1}+\beta 5 *$ Xformalcontact $_{\mathrm{t} 1}+\beta 6 * \mathrm{Xsex}_{\mathrm{t} 1}+\beta 7 * \mathrm{Xsex}_{\mathrm{t} 1}+\beta 8 * \mathrm{Xsex}_{\mathrm{t} 1}+\beta 9 * \mathrm{Xage}_{\mathrm{t} 1}$

$+\beta 10 *$ Xeducation $_{\mathrm{t} 1}+\beta 11 *$ Xethnic $_{\mathrm{t} 1}+\beta 12 *$ Xreligionattendance $_{\mathrm{t} 1}+\beta 13 *$ Xvictimhood $_{\mathrm{t} 1}+\beta 14 *$ Xpartnerproblems $_{\mathrm{t} 1}$

$+\beta 15 *$ Xhouseholdcompositiondummy $1_{\mathrm{t} 1}+\beta 16 *$ Xhouseholdcompositiondummy $2_{\mathrm{t} 1}$

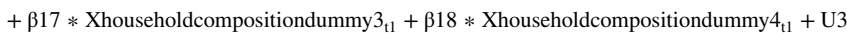

Xinformalcontact $_{\mathrm{t} 2}=\beta 1 *$ Ytrust $_{\mathrm{t} 1}+\beta 2 *$ Xhouseholdincome $_{\mathrm{t} 1}+\beta 3 *$ Xmaterialdeprivation $_{\mathrm{t} 1}$

$+\beta 4 *$ Xinformalcontact $_{\mathrm{t} 1}+\beta 5 * \mathrm{X}_{\text {formalcontact }}+\beta 6 * \mathrm{Xsex}_{\mathrm{t} 1}+\beta 7 * \mathrm{Xsex}_{\mathrm{t} 1}+\beta 8 * \mathrm{Xsex}_{\mathrm{t} 1}+\beta 9 * \mathrm{Xage}_{\mathrm{t} 1}$

$+\beta 10 *$ Xeducation $_{\mathrm{t} 1}+\beta 11 *$ Xethnic $_{\mathrm{t} 1}+\beta 12 *$ Xreligionattendance $_{\mathrm{t} 1}+\beta 13 *$ Xvictimhood $_{\mathrm{t} 1}+\beta 14 *$ Xpartnerproblems $_{\mathrm{t} 1}$

$+\beta 15 *$ Xhouseholdcompositiondummy $1_{\mathrm{t} 1}+\beta 16 *$ Xhouseholdcompositiondummy $2_{\mathrm{t} 1}$

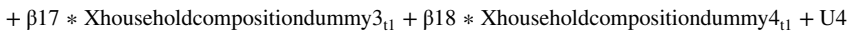

Xformalcontact $_{\mathrm{t} 2}=\beta 1 *$ Ytrust $_{\mathrm{t} 1}+\beta 2 *$ Xhouseholdincome $_{\mathrm{t} 1}+\beta 3 *$ Xmaterialdeprivation $_{\mathrm{t} 1}+\beta 4 *$ Xinformalcontact $_{\mathrm{t} 1}$

$+\beta 5 *$ Xformalcontact $_{\mathrm{t} 1}+\beta 6 * \mathrm{Xsex}_{\mathrm{t} 1}+\beta 7 * \mathrm{Xsex}_{\mathrm{t} 1}+\beta 8 * \mathrm{Xsex}_{\mathrm{t} 1}+\beta 9 * \mathrm{Xage}_{\mathrm{t} 1}+\beta 10 * \mathrm{Xeducation}_{\mathrm{t} 1}+\beta 11 * \mathrm{Xethnic}_{\mathrm{t} 1}$

$+\beta 12 *$ Xreligionattendance $_{\mathrm{t} 1}+\beta 13 *$ Xvictimhood $_{\mathrm{t} 1}+\beta 14 *$ Xpartnerproblems $_{\mathrm{t} 1}$

$+\beta 15 *$ Xhouseholdcompositiondummy $1_{\mathrm{t} 1}+\beta 16 *$ Xhouseholdcompositiondummy $2_{\mathrm{t} 1}$

$+\beta 17 *$ Xhouseholdcompositiondummy $3_{\mathrm{t} 1}+\beta 18 *$ Xhouseholdcompositiondummy $4_{\mathrm{t} 1}+\mathrm{U} 5$

\section{Fixed Effect Model (Torres-Reyna 2007)}

$$
\mathrm{Y}_{\mathrm{it}}=\beta 1 * \mathrm{X}_{\mathrm{it}}+\alpha_{\mathrm{i}}+\mathrm{U}_{\mathrm{it}}
$$

where

$-\alpha_{i}(i=1 \ldots n)$ is the unknown intercept for each entity (n entity-specific intercepts).

$-\mathrm{Y}_{\text {it }}$ is the dependent variable (DV) where $\mathrm{i}=$ entity and $\mathrm{t}=$ time.

$-\mathrm{X}_{\mathrm{it}}$ represents one independent variable (IV),

$-\beta 1$ is the coefficient for that IV,

$-\mathrm{U}_{\mathrm{it}}$ is the error term

\section{'Bivariate' Fixed Effect Model (Household Income)}

Ytrust $_{\mathrm{it}}=\beta 1 *$ Xhouseholdincome $_{\mathrm{it}}+\beta 2 * \mathrm{Xage}_{\mathrm{it}}+\beta 3 *$ Xeducation $_{\mathrm{it}}+\beta 4 *$ Xreligionattendance $_{\mathrm{it}}+\beta 5 * \mathrm{Xvictimhood}_{\mathrm{it}}$

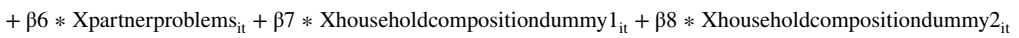

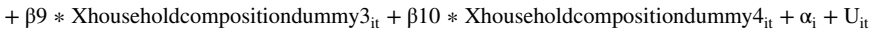

Yhouseholdincome $_{\mathrm{it}}=\beta 1 * \mathrm{Xtrust}_{\mathrm{it}}+\beta 2 * \mathrm{Xage}_{\mathrm{it}}+\beta 3 *$ Xeducation $_{\mathrm{it}}+\beta 4 *$ Xreligionattendance $_{\mathrm{it}}+\beta 5 * \mathrm{Xvictimhood}_{\mathrm{it}}$

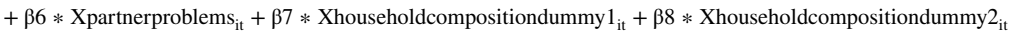

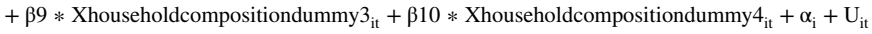




\section{'Bivariate' Fixed Effect Model (Material Deprivation)}

Ytrust $_{\mathrm{it}}=\beta 1 * \mathrm{Xmaterialdeprivation}_{\mathrm{it}}+\beta 2 * \mathrm{Xage}_{\mathrm{it}}+\beta 3 *$ Xeducation $_{\mathrm{it}}+\beta 4 *$ Xreligionattendance $_{\mathrm{it}}$

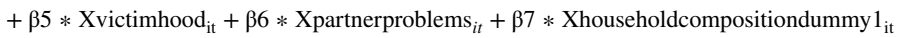

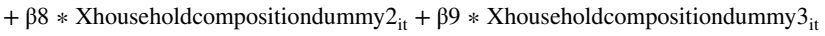

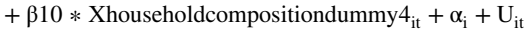

Ymaterialdeprivation $_{\mathrm{it}}=\beta 1 *$ Xtrust $_{\mathrm{it}}+\beta 2 *$ Xage $_{\mathrm{it}}+\beta 3 *$ Xeducation $_{\mathrm{it}}+\beta 4 *$ Xreligionattendance $_{\mathrm{it}}$

$+\beta 5 *$ Xvictimhood $_{\mathrm{it}}+\beta 6 *$ Xpartnerproblems $_{\mathrm{it}}+\beta 7 *$ Xhouseholdcompositiondummy $_{\mathrm{it}}$

$+\beta 8 *$ Xhouseholdcompositiondummy $2_{\text {it }}+\beta 9 *{\text { Xhouseholdcompositiondummy } 3_{\text {it }}}$

$+\beta 10 *$ Xhouseholdcompositiondummy $4_{i t}+\alpha_{i}+U_{i t}$

\section{'Bivariate' Fixed Effect Model (Informal Contact)}

Ytrust $_{\mathrm{it}}=\beta 1 *$ Xinformalcontact $_{\mathrm{it}}+\beta 2 *$ Xage $_{\mathrm{it}}+\beta 3 *$ Xeducation $_{\mathrm{it}}+\beta 4 *$ Xreligionattendanc $_{\mathrm{it}}+\beta 5 * \mathrm{Xvictimhood}_{\mathrm{it}}$

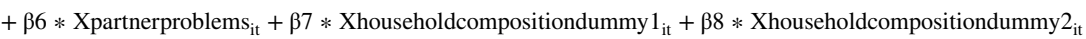

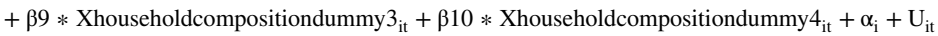

Yinformalcontact $_{\mathrm{it}}=\beta 1 *$ Xtrust $_{\mathrm{it}}+\beta 2 *$ Xage $_{\mathrm{it}}+\beta 3 *$ Xeducation $_{\mathrm{it}}+\beta 4 *$ Xreligionattendance $_{\mathrm{it}}+\beta 5 *$ Xvictimhood $_{\mathrm{it}}$

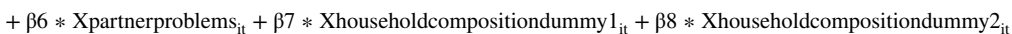

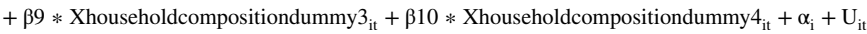

\section{'Bivariate' Fixed Effect Model (Formal Contact)}

Ytrust $_{\mathrm{it}}=\beta 1 *$ Xformalcontact $_{\mathrm{it}}+\beta 2 *$ Xage $_{\mathrm{it}}+\beta 3 *$ Xeducation $_{\mathrm{it}}+\beta 4 *$ Xreligionattendance $_{\mathrm{it}}+\beta 5 * \mathrm{Xvictimhood}_{\mathrm{it}}$

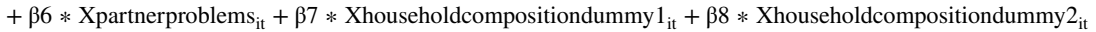

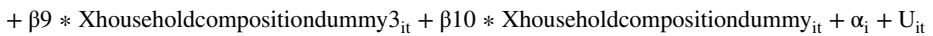

Yformalcontact $_{\mathrm{it}}=\beta 1 * \mathrm{Xtrust}_{\mathrm{it}}+\beta 2 * \mathrm{Xage}_{\mathrm{it}}+\beta 3 *$ Xeducation $_{\mathrm{it}}+\beta 4 *$ Xreligionattendance $_{\mathrm{it}}+\beta 5 * \mathrm{Xvictimhood}_{\mathrm{it}}$

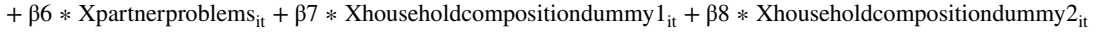

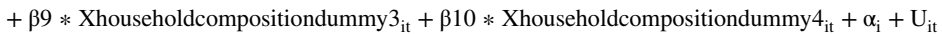

\section{Full Fixed Effect Model}

Ytrust $_{\mathrm{it}}=\beta 1 *$ Xhouseholdincome $_{\mathrm{it}}+\beta 2 *$ Xmaterialdeprivation $_{\mathrm{it}}+\beta 3 *$ Xinformalcontact $_{\mathrm{it}}+\beta 4 *$ Xformalcontact $_{\mathrm{it}}$

$+\beta 5 *$ Xage $_{\mathrm{it}}+\beta 6 *$ Xeducation $_{\mathrm{it}}+\beta 7 *$ Xreligionattendance $_{\mathrm{it}}+\beta 8 *$ Xvictimhood $_{\mathrm{it}}+\beta 9 * \mathrm{Xpartnerproblems}_{\mathrm{it}}$

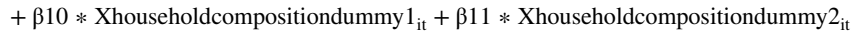

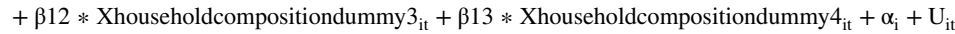


Yhouseholdincome $_{\mathrm{it}}=\beta 1 *$ Xtrust $_{\mathrm{it}}+\beta 2 *$ Xmaterialdeprivation $_{\mathrm{it}}+\beta 3 *$ Xinformalcontact $_{\mathrm{it}}+\beta 4 *$ Xformalcontact $_{\mathrm{it}}$

$+\beta 5 *$ Xage $_{\mathrm{it}}+\beta 6 *$ Xeducation $_{\mathrm{it}}+\beta 7 *$ Xreligionattendance $_{\mathrm{it}}+\beta 8 *$ Xvictimhood $_{\mathrm{it}}+\beta 9 * \mathrm{Xpartnerproblems}_{\mathrm{it}}$

$+\beta 10 *$ Xhouseholdcompositiondummy $1_{\text {it }}+\beta 11 *$ Xhouseholdcompositiondummy $2_{\text {it }}$

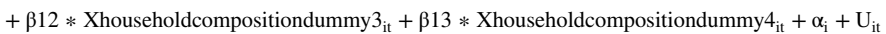

Ymaterialdeprivation $_{\mathrm{it}}=\beta 1 *$ Xtrust $_{\mathrm{it}}+\beta 2 *$ Xmaterialdeprivation $_{\mathrm{it}}+\beta 3 *$ Xinformalcontact $_{\mathrm{it}}+\beta 4 * \mathrm{Xformalcontact}_{\mathrm{it}}$

$+\beta 5 *$ Xage $_{\mathrm{it}}+\beta 6 *$ Xeducation $_{\mathrm{it}}+\beta 7 *$ Xreligionattendance $_{\mathrm{it}}+\beta 8 *$ Xvictimhood $_{\mathrm{it}}+\beta 9 * \mathrm{Xpartnerproblems}_{\mathrm{it}}$

$+\beta 10 *$ Xhouseholdcompositiondummy $1_{\text {it }}+\beta 11 *$ Xhouseholdcompositiondummy $2_{\text {it }}$

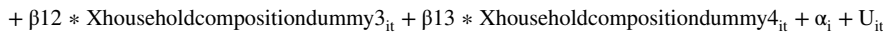

Yinformalcontact $_{\mathrm{it}}=\beta 1 *$ Xtrust $_{\mathrm{it}}+\beta 2 *$ Xmaterialdeprivation $_{\mathrm{it}}+\beta 3 *$ Xinformalcontact $_{\mathrm{it}}+\beta 4 * \mathrm{Xformalcontact}_{\mathrm{it}}$

$+\beta 5 *$ Xage $_{\mathrm{it}}+\beta 6 *$ Xeducation $_{\mathrm{it}}+\beta 7 *$ Xreligionattendance $_{\mathrm{it}}+\beta 8 *$ Xvictimhood $_{\mathrm{it}}+\beta 9 *$ Xpartnerproblems $_{\mathrm{it}}$

$+\beta 10 *$ Xhouseholdcompositiondummy $1_{\text {it }}+\beta 11 *$ Xhouseholdcompositiondummy $2_{\text {it }}$

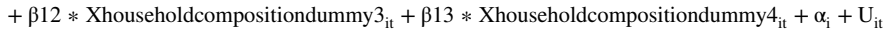

Yformalcontact $_{\mathrm{it}}=\beta 1 *$ Xtrust $_{\mathrm{it}}+\beta 2 *$ Xmaterialdeprivation $_{\mathrm{it}}+\beta 3 *$ Xinformalcontact $_{\mathrm{it}}+\beta 4 *$ Xformalcontact $_{\mathrm{it}}$

$+\beta 5 *$ Xage $_{\mathrm{it}}+\beta 6 *$ Xeducation $_{\mathrm{it}}+\beta 7 *$ Xreligionattendance $_{\mathrm{it}}+\beta 8 *$ Xvictimhood $_{\mathrm{it}}+\beta 9 * \mathrm{Xpartnerproblems}_{\mathrm{it}}$

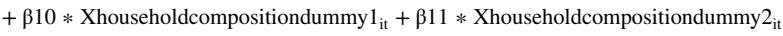

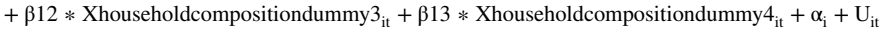

Ymaterialdeprivation $_{\mathrm{it}}=\beta 1 *$ Xtrust $_{\mathrm{it}}+\beta 2 * \mathrm{Xage}_{\mathrm{it}}+\beta 3 *$ Xeducation $_{\mathrm{it}}+\beta 4 *$ Xreligionattendance $_{\mathrm{it}}$

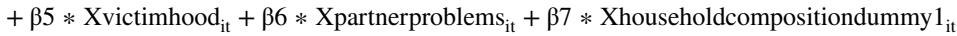

$+\beta 8 *$ Xhouseholdcompositiondummy $2_{\text {it }}+\beta 9 *{\text { Xhouseholdcompositiondummy } 3_{\text {it }}}$

$+\beta 10 *$ Xhouseholdcompositiondummy $_{i t}+\alpha_{i}+U_{i t}$

Open Access This article is licensed under a Creative Commons Attribution 4.0 International License, which permits use, sharing, adaptation, distribution and reproduction in any medium or format, as long as you give appropriate credit to the original author(s) and the source, provide a link to the Creative Commons licence, and indicate if changes were made. The images or other third party material in this article are included in the article's Creative Commons licence, unless indicated otherwise in a credit line to the material. If material is not included in the article's Creative Commons licence and your intended use is not permitted by statutory regulation or exceeds the permitted use, you will need to obtain permission directly from the copyright holder. To view a copy of this licence, visit http://creativecommons.org/licenses/by/4.0/.

\section{References}

Acedo-Carmona, C., \& Gomila, A. (2014). Personal trust increases cooperation beyond general trust. PLoS ONE, 9(8), 1-10.

Alesina, A., \& La Ferrara, E. (2002). Who trusts others? Journal of Public Economics, 85(2), 207-234.

Allison, P. D. (2005a). "Causal inference with panel data." Paper presented at the Annual Meeting of the American Sociology Association. Philadelphia: ASA.

Allison, P. D. (2005b). Fixed effects regression methods for longitudinal data using SAS. North Carolina: SAS Institute. 
Almakaeva, A., Ponarin, E., \& Welzel, C. (2014). Human development and generalized trust: Multilevel evidence. WP BRP Series Sociology/SOC: 1-27.

Bekkers, R. (2012). Trust and volunteering: Selection or causation? Evidence from a four year panel study. Political Behavior, 34(2), 225-247.

Brandt, M. J., Wetherell, G., \& Henry, P. J. (2015). Changes in income predict change in social trust: A longitudinal analysis. Political Psychology, 36, 761-768.

Brehm, J., \& Rahn, W. (1997). Individual-level evidence for the causes and consequences of social Capital. American Journal of Political Science, 41(3), 999-1023.

Claibourn, M. P., \& Martin, P. S. (2000). Trusting and joining? An empirical test of the reciprocal nature of social capital. Political Behavior, 22(4), 267-291.

Colman, A. M. (2003). Cooperation, psychological game theory, and limitations of rationality in social interaction. Behavioural and Brain Sciences, 26(2), 139-198.

Dauner, K. N., Wilmot, N. A., \& Schultz, J. F. (2015). Investigating the temporal relationship between individual-level social capital and health in fragile families. BMC Public Health, 15(1), 1130.

Delhey, J., \& Newton, K. (2003). Who trusts? The origins of social trust in seven societies. European Societies, 5(2), 93-137.

Delhey, J., \& Newton, K. (2005). Predicting cross-national levels of social trust: Global pattern or Nordic exceptionalism? European Sociological Review, 21(4), 311-327.

Dunn, J. R., \& Schweitzer, M. E. (2005). Feeling and believing: The influence of emotion on trust. Journal of Personality and Social Psychology, 88(5), 736-748.

Durkheim, E. 1964([1893]). The division of labor in society. Glencoe, IL: The Free Press.

Finkel, S. E. (1995). Causal analysis with panel data. Beverly Hills: Sage Publications.

Finkel, S. E. (2008). Linear Panel analysis. In S. Mernard (Ed.), Handbook of longitudinal research: Design measurement and analysis. Massachusetts: Academic Press.

Freitag, M., \& Traunmüller, R. (2009). Spheres of trust: An empirical analysis of the foundations of particularised and generalised trust. European Journal of Political Research, 48(6), 782-803.

Fukuyama, F. (1995). Trust: Social virtues and the creation of prosperity. New York: Free Press.

Gächter, S. (2006). Conditional cooperation: behavioral regularities from the lab and the field and their policy implications. CeDEx Discussion Paper No. 2006-03.

Glanville, J. L., Andersson, M. A., \& Paxton, P. (2013). Do social connections create trust? An examination using new longitudinal data. Social Forces, 92(2), 545-562.

Glanville, J. L., \& Paxton, P. (2007). How do we learn to trust? A confirmatory tetrad analysis of the sources of generalized trust. Social Psychology Quarterly, 70(3), 230-242.

Granovetter, M. S. (1973). The strength of weak ties. American Journal of Sociology, 78(6), 1360-1380.

Gujarati, D. N. (2003). Basic econometrics. New York: McGraw Hill.

Halleröd, B., \& Larsson, D. (2008). Poverty, welfare problems and social exclusion. International Journal of Social Welfare, 17, 15-25.

Hamamura, T. (2012). Social class predicts generalized trust, but only in wealthy societies. Journal of Cross-Cultural Psychology, 43(3), 498-509.

Jöreskog, K.G., \& Sörbom, D. (2006). LISREL 8.80 for Windows [Computer Software]. Illinois: SSI, Inc.

Kline, P. (2000). The handbook of psychological testing (2nd ed.). London: Routledge.

Knack, S., \& Keefer, P. (1997). Does social capital have an economic payoff? A cross-country investigation. The Quarterly Journal of Economics, 112(4), 1251-1288.

Lin, N. (2001). Social capital: A theory of structure and action. New York: Cambridge, University Press.

Lin, N. (2005). A network theory of social capital. In D. Castiglione, J. W. van Deth, \& G. Wolleb (Eds.), The handbook of social capital. Oxford: Oxford University Press.

Mcpherson, M., Smith-Lovin, L., \& Cook, J. M. (2001). Birds of a feather: Homophily in social networks. Annual Review of Sociology, 27, 415-444.

Merton, R. K. (1938). Social structure and anomie. American Sociological Review, 3(5), 672-682.

Messner, S. F., Baumer, E. P., \& Rosenfield, R. (2004). Dimensions of social capital and rates of criminal homicide. American Sociological Review, 69(6), 882-903.

Nakhaie, R., \& Arnold, R. (2010). A four year (1996-2000) analysis of social capital and health status of Canadians: The difference that love makes. Social Science and Medicine, 71(5), 1037-1044.

Nannestad, P. (2008). What have we learned about generalized trust, if anything? Annual Review of Political Science, 11, 413-436.

Nilsson, M., \& Mattes, J. (2015). The spatiality of trust: factors influencing the creation of trust and the role of face-to-face contacts. European Management Journal, 33(4), 230-244.

OECD (2009). "What are equivalence scales?” Retrieved October 27, 2017 from http://oedc.org/eco/growth. 
Paxton, P. (2007). Association memberships and generalized trust: A multilevel model across 31 countries. Social Forces, 81(6), 47-76.

Pruitt, D. G., \& Kimmel, M. J. (1977). Twenty years of experimental gaming: Critique, synthesis, and suggestions for the future. Annual Review of Psychology, 28, 363-392.

Putnam, R. D. (2000). Bowling Alone: The collapse and revival of American community. New York: Simon \& Schuster.

Ritzen, J., Easterly, W., \& Woolcock, M. (2000). On "good" politicians and "bad" policies—social cohesion, institutions, and growth. Policy Research Working Paper no. WPS 2448. Washington, DC: World Bank.

Rosenblum, N. L. (1998). Membership and morals: The personal uses of pluralism in America. New Jersey: Princeton University Press.

Sønderskov, K. M. (2011). Does generalized trust lead to associated membership? Unravelling a bowl of well-tossed spaghetti. European Sociological Review, 27(4), 419-434.

Sønderskov, K. M., \& Dinesen, P. T. (2016). Trusting the state, trusting each other? The effect of institutional trust on social trust. Political Behavior, 38, 179-202. https://doi.org/10.1007/s11109-015-9322-8.

Stolle, D. (1998). Why do bowling and singing matter? Group characteristics, membership, and generalized trust. Political Psychology, 19(3), 497-525.

Stolle, D. (2001). Clubs and congregations: The benefits of joining an association. In K. S. Cook (Ed.), Trust in society. New York: Russell Sage Foundation.

Sturgis, P., Patulny, R., Allum, N., \& Buscha, F. (2012). Social Connectedness and Generalized Trust: A Longitudinal Perspective. Paper No. 2012-19. Institute for Social \& Economic Research.

Tolsma, J., Kraaykamp, G., de Graaf, P. M., Kalmijn, M., \& Monden, C. W. S. (2014). The NEtherlands Longitudinal Lifecourse Study (NELLS. Panel): Dataset. Radboud University Nijmegen, Tilburg University \& University of Amsterdam, Netherlands.

Tooby, J., Cosmides, L., \& Price, M. (2006). Cognitive adaptations for n-person exchange: The evolutionary roots of organizational behavior. Managerial and Decision Economics, 27(2-3), 103-129.

Torres-Reyna, O. (2007). Panel data analysis fixed and random effects using stata. Retrieved from http:// dss.princeton.edu/training/.

Turner, J. H. (2002). Face to face: Towards a sociological theory of interpersonal behavior. California: Stanford University Press.

Uslaner, E. (2002). The moral foundations of trust. Cambridge, UK: Cambridge University Press.

Van Ingen, E., \& Bekkers, R. (2015). Generalized trust through civic engagement? Evidence from five national panel studies. Political Psychology, 35(3), 277-294.

Weining, A. N., \& Smith, E. L. (2012). Self-esteem and trust: correlation between self-esteem and willingness to trust in undergraduate students. Inquiries Journal: Student Pulse, 4(8), 1-2.

Welch, M. R., Sikkink, D., \& Loveland, M. T. (2007). The radius of trust: Religion, social embeddedness and trust in strangers. Social Forces, 86(1), 23-46.

Whelan, C. T., Layte, R., Maître, B., \& Nolan, B. (2001). Income, deprivation, and economic strain: An analysis of the European Community Household Panel. European Sociological Review, 17, 357-372.

Wollebaek, D., \& Selle, P. (2002). Does participation in voluntary associations contribute to social capital? The impact of intensity, scope, and type. Nonprofit and Voluntary Sector Quarterly, 31(1), 32-61.

Publisher's Note Springer Nature remains neutral with regard to jurisdictional claims in published maps and institutional affiliations. 